\title{
EDITORIAL
}

\section{Peer review e as cinco funções docentes}

$\mathrm{A}$ seriedade da atividade científica divulgada em revistas especializadas está fundada em dois pressupostos fundamentais: na veracidade das informações fornecidas pelo pesquisador no manuscrito e na imparcialidade do julgamento do mesmo pelos membros da comunidade científica, no processo internacionalmente adotado e conhecido como "julgamento por pares" ou peer review. Infelizmente, tratando-se de valores de ética científica dependentes da natureza humana e difíceis de monitorar, estes princípios são muitas vezes subvertidos, gerando, respectivamente, publicações fraudulentas e decisões editoriais preconceituosas, causando grandes injustiças e descrédito à investigação científica.

Estes temas foram discutidos, pela primeira vez em grande escala, em um evento recente ( The International Congress on Biomedical Peer Review and Global Communication) realizado em Praga, na República Tcheca, entre 17 e 21 de setembro último, financiado pela organização não-governamental americana Project Hope e pelas associações médicas americana e inglesa. O congresso foi precedido por um seminário, destinado a editores de pequenas revistas médicas, predominantemente do $3^{\circ}$ mundo, como a nossa, objetivando melhorar a qualidade dos trabalhos nelas publicados, pelo aperfeiçoamento da captação e da seleção dos artigos. Houve uma interação profícua com editores das cinco mais prestigiosas publicações médicas gerais do planeta (Annals of Internal Medicine, British Medical Journal, JAMA, Lancet e New England Journal of Medicine), além da Science e de algumas revistas especializadas. Durante o evento, foi fundada a Associação Mundial dos Editores Médicos (WAME), com o objetivo de perenizar esta interação e de investigar e lutar contra os preconceitos ("bias") presentes nas várias etapas do julgamento editorial.

Nos 120 trabalhos apresentados (72 orais e 48 posters), foram analisados inúmeros fatores que interferem na objetividade, equanimi- dade e, em última análise, na qualidade do processo de peer review, como a influência do sexo, procedência, etnia, língua e da identificação ou não dos autores e dos revisores (blind review). $O$ que é mais importante, muitos destes tópicos foram abordados com uma metodologia de investigação científica, de natureza sociológica, e os resultados obtidos estão começando a se traduzir no monitoramento mais preciso do trabalho dos revisores e em instruções mais detalhadas para aumentar sua eficiência e reduzir bias de várias naturezas que o contaminam.

Em uma investigação do Gastrenterology, por exemplo, verificou-se que revisores americanos ranqueiam e recomendam a aceitação direta de trabalhos provenientes dos EUA com escores e em proporções significantemente superiores aos de revisores não-americanos $(p<0.001)$. A existência de preconceitos, especificamente em relação à ciência do III mundo, ficou claramente evidenciada na intervenção do editor-chefe do New England Journal of Medicine, Jerome Kassirer. Confirmando declarações à Scientific American (ago/95) citadas em editorial desta Revista (n. 2/95), afirmou que estes países necessitam de recursos básicos, como vacinas e remédios, não de atividade científica. Exemplificou que presenciara na Rússia enfermarias com 40 leitos sem nenhuma pia, problema não solucionável nem com ciência nem com informação. Foi interpelado publicamente por um representante russo e por nós, privadamente, replicando, então, que a ciência deveria ser aplicada à solução dos problemas do país e que considerava anti-ético dispender grandes recursos em pesquisa diletante em uma nação, como a nossa, com os desequilíbrios sociais típicos de uma "Belíndia".

\section{PEER REVIEWS "BIASADOS" POR EMINENTES CIENTISTAS}

Todos nós, certamente, temos mais de um exemplo a mostrar de subjetividade e parcialidade, muitas vezes destrutivas, em decisões tomadas 
por nossos pares, ainda que sejam eminentes e insuspeitos cientistas. Estas decisões se aplicam não só a trabalhos científicos submetidos a publicação ou a apresentação em congressos, mas, em um sentido mais amplo, ao julgamento de concursos, processos seletivos, projetos de pesquisa e a toda matéria que envolva mérito acadêmico.

Esta Revista foi vítima, no ano passado, de uma destas decisões, quando se submeteu a credenciamento no "Programa de Apoio às Publicações Científicas Periódicas da USP". Dois revisores não identificados que examinaram números recentes da Revista exararam os seguintes comentários: 1) a) "A Revista Medicina é uma publicação de interesse local, útil aos alunos de graduação e que serve como veículo para publicação de artigos pouco competitivos, didáticos ou sobre problemas da própria comunidade"; b) "Quanto à qualidade, os artigos de revisão são muito bons; os artigos originais são menos interessantes e os resumos de teses podem ser úteis como uma forma de avaliar a pós-graduação da FMRP”; c) São publicados 4 números por ano, porém não creio que esta periodicidade venha sendo mantida. Os artigos são todos em Português. Estas características dificultam que ela seja indexada; sendo uma revista bem antiga, não creio que tenha sido indexada"; d) "A produção da FMRP costuma ser muito boa e é veiculada em periódicos indexados de rigorosa política editorial...não creio que "Medicina" seja um periódico atrativo para os próprios pesquisadores de Ribeirão Preto". 2) a) "A revista MEDICINA destina-se a trabalhos de Medicina em geral, o que a torna de difícil avaliação c) Lembramos que um grande número de revistas científicas com capacidade editorial discutível está aparecendo nestes últimos tempos".

Baseando-se nestes comentários, a Comissão de Periódicos da USP emitiu o seguinte parecer, assinado por seu presidente, um eminente cientista do Instituto de Ciências Biomédicas da Universidade: "Após discussão e constatação de tratar-se de um periódico que atende uma comunidade local, tendo em vista que há muitos outros periódicos que cobrem adequadamente a área, e em comparação com a qualidade dos demais periódicos existentes na área, (a Comissão) optou pelo não credenciamento do mesmo".
Torna-se cansativo e desnecessário rebater cada argumento apresentado pelos relatores, mas argumento final e decisivo merece consideração. Os dois números da Revista encaminhados para análise da Comissão continham, respectivamente, Simpósios temáticos sobre Bioética e Síndrome do Intestino Curto, além de artigos enfocando, entre outros assuntos, 1) imunohistoquímica aplicada ao diagnóstico anátomo-patológico, 2) violência doméstica em adolescentes de Caxias do Sul-RJ, 3) surto de pênfigo foliáceo em Batatais-SP, 4) esofagite de refluxo, 5) patogenia das viroses do sistema nervoso, 6) emergências psiquiátricas atendidas em pronto-socorro geral, 7) problemas diagnósticos na tuberculose óssea, 8) precisão do teste de Elisa para HIV-1, 9) acidentes de trabalho em destilarias de álcool da região de Ribeirão Preto, 10) recolocação social em pacientes submetidos a cirurgia de revascularização miocárdica no Instituto Dante Pazzanese-SP, 11) modelo experimental de cistometria em ratos e 12) atitudes de estudantes de medicina em relação à doação sangüínea.

Seria justo enfeixar estes artigos como tendo apenas "interesse local"? Mesmo aqueles de cunho epidemiológico ou médico-social, derivados de estudos comunitários, não deixam lições que extrapolam o local onde foram realizados? A descrição, por exemplo, de um surto de pênfigo foliáceo em uma pequena cidade, seja onde for, só teria interesse para o lugar onde ocorreu? Além de ser distribuída gratuitamente aos membros da "comunidade local" médico-acadêmica, a Revista integra o Index Médico Latino-Americano (LILACS) e é enviada a cerca de quatrocentas bibliotecas biomédicas da América Latina e a cerca de 50 hospitais filantrópicos do estado de SP.

Quanto à qualidade da Revista "em comparação com a dos demais periódicos existentes na área”, trata-se de uma análise difícil de ser feita, pois a única outra revista médica geral da USP é a do HC-SP, de escopo diferente da nossa, pois não publica simpósios temáticos e, praticamente, nenhuma revisão. Este conteúdo editorial, de interesse didático, não predomina na grande maioria das revistas médicas brasileiras, ao contrário da nossa, mas, certamente, se adequa melhor ao perfil de uma publicação universitária. 
Diante da flagrante parcialidade do julgamento da Comissão de Credenciamento da USP, nem nos animamos a recorrer de sua decisão. Ao contrário, obtivemos financiamento da iniciativa privada e investimos na modernização gráfica da Revista, como destacado no número 1/97 (Nota do editor, pg. 4).

Outro eminente cientista brasileiro, agora da Escola Paulista de Medicina, presidiu recentemente o Comitê da Academia Brasileira de Ciências para seleção de candidatos à bolsa de pós-doutorado do Fogarty International Center/NIH/USA. Havendo 3 candidatos para 6 vagas, foi indicado apenas um dos candidatos e outro, por coincidência, das minhas relações, foi recusado com o argumento de "overqualification", ou seja, apresentava, no projeto de pesquisa, qualificações supostamente superiores às exigidas pelo programa, indicativas da participação "exagerada" do orientador na elaboração do projeto. A réplica do orientador, outro eminente cientista, da Universidade de Harvard/EUA, é auto-explicativa: "It is true that I had considerable influence on the area that she presented in her application, but I thought this was necessary, since her ultimate productivity in my laboratory during the relatively short period of two years would depend upon her working in an area that my laboratory already has much experience and commitment towards. If the application appears to be too complex, the blame is with me, not with her. She is one of the most talented applicants I have seen outside of the USA".

Vê-se por esses exemplos, e por muitos outros não citados, que pesquisadores justamente reconhecidos e respeitados por seu trabalho científico não estão isentos de julgamentos distorcidos a respeito do trabalho alheio. Isto ocorre porque estes julgamentos envolvem valores de ética e filosofia científicas facilmente "biasáveis', independentemente da competência técnica específica de quem detém o "poder" de emitir pareceres ou de tomar decisões de mérito científico-acadêmico.

\section{A QUÁDRUPLA OU QUÍNTUPLA FUNÇÃO DOCENTE}

Aludimos, no editorial do último número da Revista (v. 30 n. 2, pg. 151-54) à quádrupla função docente na Universidade (didática, científica, assistencial e administrativa). O professor Harry Jacob, da Universidade de Minnesota e Vice-Presidente da Associação Americana de Hematologia, considera a quarta função docente como o tutoramento de estudantes mais jovens na aquisição de sua formação técnica e seus padrões éticos. Em um editorial recente (Mentoring: the forgotten fourth leg of the academic stool, J Lab Clin Med 129: 486, 1997), cita o presidente da New York Academy of Sciences, Jerry Barondes, para quem "as atividades de tutoramento representam um poderoso foco na medicina acadêmica porque contribuem crucialmente para as prioridades, estilos e padrões da carreira dos futuros docentes e, deste modo, moldam a medicina do futuro" (Mentoring in Biomedicine, idem, p. 487-491).

O prof. Jacob relata ainda que, tendo sido encarregado de elaborar uma nova estratégia para medir e recompensar a "produtividade" dos docentes do seu departamento, tem muita dificuldade em fazê-lo para o tutoramento, o qual, por isto, permanece negligenciado na maioria das instituições acadêmicas americanas. Acrescenta: "Nossos técnicos administrativos são capazes de rastrear fundos decorrentes de atividade clínica e de projetos de pesquisa com grande acurácia e transformá-los em medida de produtividade. Entretanto, suspeito que "produtividade" não se equipara a importância em nossa profissão médica, fundada no mandamento hipocrático de que profissionais maduros transmitam experiência e sabedoria a aprendizes criativos e energéticos, o que constitui o mandato do tutoramento. Embora se reconheça que as fórmulas de remuneração devam incluir os esforços didáticos dos docentes, difíceis de quantificar, a concretização deste louvável objetivo - além do nível de abundante retórica - permanece atualmente bastante obscura na maioria das instituições. No máximo, a quantidade, raramente a qualidade, do ensino é considerada na maioria das fórmulas. e... este reconhecido quarto aspecto da atividade acadêmica - o tutoramento - é, em geral, completamente ignorado nas fórmulas usadas para calcular a remuneração docente." E finaliza: "as autoridades universitárias devem começar a reconhecer e estimular os esforços tutorais dos docentes, os quais, sem este encorajamento, certamente se dirigirão para tarefas mais facilmente quantificáveis e remuneradas". 
Poder-se-ia argumentar que o tutoramento não constitui uma atividade docente à parte (the fourth leg) das funções didáticas de graduação e de pós-graduação. Talvez esta superposição seja real para a formação de pós-graduandos, em que a relação pessoal orientando-orientador é condição intrínseca do programa. Entretanto, nosso modelo conservador de educação graduada envolve poucos docentes em atividades tutoradas, predominantemente nos últimos anos do curso. Por outro lado, a supervisão de alunos monitores, aprimorandos, estagiários e, principalmente, de médicos residentes e assistentes, consome, em muitos casos, a maior parte do tempo e energia do docente clínico e produz uma plêiade valiosa de profissionais diferenciados para o mercado ou para a própria instituição. Estas atividades têm sido, recentemente, remuneradas, embora de maneira homogênea, pelos hospitais universitários através de bolsas de complementação salarial. Entretanto, não são avaliadas e têm pouco valor nos concursos universitários.

Na realidade universitária européia ou norte-americana, ao contrário da nossa, o exercício do poder centralizado na figura de chefes cuidadosamente selecionados ("déspotas esclarecidos") poupa o corpo docente da maioria das funções político-administrativas (participação em órgãos colegiados e comissões, lobbies políticos, pareceres técnicos, etc.) presentes em nosso modelo de gestão mais democrático. Deste modo, é legítimo caracterizar estas funções como o quinto ramo (fifth leg) da atividade acadêmica, um a mais do que as prevalentes nos países do $1^{0}$ mundo. Tanto lá como aqui, entretanto, há uma tendência do docente que se dedica à administração universitária de se afastar das atividades-fim, que constituem o objeto da existência da Universidade. Quando isto ocorre por tempo prolongado, assistimos, não raramente, à adoção de políticas e normas completamente dissociadas da realidade e das necessidades institucionais.

\section{PEER REVIEWCOMO FUNÇÃO DOCENTE}

A pletora de pareceres técnicos e administrativos que povoa nossa mesa de trabalho no dia-a-dia da atividade universitária compõe, certamente, uma parte considerável das funções científica e administrativa do docente. Exercer o julgamento crítico sobre o trabalho de colegas ou sobre questões político-administrativas que repercutirão na comunidade requer, além da pressuposta capacidade técnica, equilíbrio emocional que assegure objetividade de opinião, autopoliciamento constante contra nossos inevitáveis preconceitos e, muitas vezes, um esforço de investigação incomputável nos relatórios de atividade docente.

O processo de peer review, no conceito amplo que o empregamos aqui, é uma atividade solitária, de grande responsabilidade e que, até há bem pouco tempo, não dispunha de qualquer parâmetro objetivo que pudesse orientar o revisor. As investigações embrionárias sobre vários aspectos do processo, como as relatadas no congresso de Praga e as que estão surgindo em algumas revistas biomédicas, começam a mudar este panorama. Desnudando as principais armadilhas que impedem um julgamento objetivo dos artigos e propiciando orientações mais estruturadas para este julgamento, auxiliam significativamente o trabalho dos revisores e criam condições para se medir a eficiência de seu desempenho

O tutoramento de aprendizes, em seus vários níveis, e a emissão de pareceres científicos ou político-administrativos constituem dois importantíssimos aspectos da atividade universitária pouco refletidos e valorizados. Neste momento, começa-se a se criarem condições para se avaliar seus méritos e se aperfeiçoar sua operação. Serão, entretanto, funções universitárias que sempre dependerão de uma grande dose de toque e inspiração pessoais, onde a experiência vivida e os valores éticos e filosóficos contam tanto quanto o preparo técnico especializado.

$$
\begin{gathered}
\text { Prof. Dr. Júlio C. Voltarelli } \\
\text { Editor }
\end{gathered}
$$

